\title{
Needlestick Puncture
}

National Cancer Institute

\section{Source}

National Cancer Institute. Needlestick Puncture. NCI Thesaurus. Code C50665.

A penetrating stab wound from a needle (or other sharp object) that may result in exposure to blood or other body fluids. 